\title{
Creativity is Collective
}

Psychologists and other commentators have always treated creativity as the ultimate expression of human individuality. However, to fully understand creativity we need to look beyond the individual: Groups and social context give creativity both form and force.

S. Alexander Haslam, Inmaculada Adarves-Yorno, Tom Postmes

Creativity is one of the most important and celebrated features of human endeavour [Box 1]. Every year, a multitude of awards are given out to recognize, celebrate, and reward the innovative creations of great individuals. The Oscars, the Man Booker, the Nobels. Such events feed into a popular conception that creativity is a gift than only certain people possess, and something that constitutes the apotheosis of individuals' individuality. To capture the essence of the topic, more than 150 books in the field pay homage to Edward de Bono by reproducing his famous line that "creativity involves breaking out of established patterns in order to look at things in a different way". At the same time we are generally led to believe that groups, and the pressure to conform to their strictures, spell death for creativity. Accordingly, some have seen the notion of "group creativity" as a contradiction in terms, thereby echoing Einstein's observation that "Everything that is really great and inspiring is created by the individual who can labor in freedom". 
But let's think creatively here. What if this basic assumption is wrong? Indeed, what might we discover if we started from the premise that groups are the foundation of creativity — essential not only for the production and form of novel creations but also for their appreciation and impact? As we will see, although at first this proposition might seem preposterous, if not treasonous, it is one for which there is now quite a lot of scientific support. As we argue in a review of the field that was published in 2013 in Personality and Social Psychology Review, it is a mistake to separate the creativity of individual minds, from the communities and social groups through which they flourish.

\section{Groups and creativity}

What possible basis could there be for thinking that creativity is a group process? We think there are at least three good reasons. The first is simply that individual-focused approaches are not that good at predicting creative behaviour. Thus while it is possible to study the biographies of creative geniuses and point to aspects of their personal history and character that made them great, attempts to identify the individual characteristics of young people who later develop into creative geniuses have been far less successful. A key reason for this is that individual approaches tend to overlook the role of context in creativity. To appreciate this point, ask yourself this question: if a genius like Bruce Springsteen had been born in 1749 rather than 1949 would he still have written Born to Run? And if the Italian Composer Domenic Cimarosa had been born in 1949 rather than 1749 would he still have penned 80 operas including his masterpiece Il matrimonio segreto? Clearly the answer to both questions is 'no'. The reason for this is that, although clearly unique, both musicians' work was heavily structured by the sensibilities of the groups for whom they were creating. 
Moreover, this explains why your own $\mathrm{CD}$ collection is far more likely to contain a Springsteen album than a Cimarosa Opera.

Second, as Vera John-Steiner, Professor of Linguistics and Education at the University of New Mexico, notes in her 2000 book Creative Collaboration, artists, writers, and scientists often do their most creative work when collaborating with one or more other people: with like-minded friends, colleagues, and peers. Indeed, innovation in society is routinely spearheaded by small groups (e.g., The Beatles, Bauhaus, The Bloomsbury Set) who "bounce off each other" in the process finding new ways to tackle traditional activities.

Third, the role of groups becomes even more clear once one appreciates that the creative process involves at least three distinct steps: (a) the generation of ideas, (b) the appraisal of ideas, and (c) the influence of ideas. Clearly in the last two of these steps input from other people plays a critical role. Thus, despite the calibre of his painting, Vincent van Gogh's creativity was not recognized — and certainly never celebrated — until a group of people had learned to appreciate it. Moreover, it was only when his work had come to epitomize the perspective of a particular group (the impressionists) that his influence really took hold.

Indeed, when we look at the generation of ideas, it is apparent that even here the group is often a latent force. For despite the stereotypic belief that innovation is the province of rugged creators who slave away in "splendid isolation", many creators have an implicit sense of there being a particular audience for their work. Thus the things that they create are often responses to the perceived needs of a particular group (e.g., for a solution to a particular problem, or for a particular type of product) and the form that these take is referenced by the values and understandings of that group. 
Interestingly too, even when creators' work is inspired by the need to "break away", this act still demands some familiarity with what is being broken away from, and hence is still very much shaped by the group from which they wanted to deviate. For example, in the 1970s, the Sex Pistols' punk rock arose from a rejection of the orthodoxies of mainstream popular music of the time. But the paradox of Sid Vicious's rallying call to "undermine [the establishment's] pompous authority, reject their moral standards, make anarchy and disorder your trademarks", is that the music establishment of the time was an essential driver of his creative force and something that gave it a very specific trajectory and very specific appeal. So the sex pistols' call to break up "the system" was not just the expression of individual desire: it was part of a collective wish to try something different.

\section{A social identity model of creativity}

So having established that groups may indeed have a role to play in creativity let us explore this idea in more depth. We can do this with reference to a new analysis of creativity that is informed by insights from research into issues of social identity. This work was pioneered in the 1970s by two British psychologists from the University of Bristol, Henri Tajfel and John Turner. One of their foundational ideas was that across a range of contexts individuals can define and categorize themselves either in terms of personal identity (as unique individuals — 'I', and 'me') or in terms of social identity (as members of the groups to which they belong — 'us' and 'we'). For example, a cubist painter, Pablo, could categorize himself either as an individual (i.e., 'I, Pablo') or as a member of his artistic group (i.e., 'us cubists' or 'I, the cubist, Pablo'). 
Tajfel and Turner argued that there are a large range of contexts in which people's sense of self is defined by social identity (e.g., as an American, a woman, a Catholic, a member of a particular organization). Moreover, under these circumstances individuals' behaviour will generally be structured by their membership in the group in question. Furthermore, evaluations of their own and others' actions should also reflect shared understandings of that group.

One direct implication of this for creativity is that when social identity defines a person's sense self (i.e., when a particular group membership is psychologically salient), creative behavior and evaluation will tend to be informed by group values, preferences and norms. So, for example, as a cubist, Pablo will be interested in, and appreciate the value of, abstract representations of objects and he will be more likely to paint and evaluate other paintings in ways that accord with, and advance, cubist artistic guidelines and preferences. In Picasso’s words, “we must pick out what is good for us where we can find it." [Box 2]

\section{Being creative}

One of the important functions of social identity is to provide a basis for people to have a shared perspective on social reality and to engage in mutual social influence. This means in those contexts where people perceive themselves to share the same group membership, they will try to co-ordinate their behavior with reference to beliefs, values, and norms by which the group is defined. In other words, when they act as group members, individuals are likely to lay down and follow group norms that define what it means to be 'one of us'. However, if their behavior is informed by an alternative identity (either as an 
individual or as a member of a different group) then they are likely to display creativity by deviating from the prevailing norm.

In line with this rationale, some of our own experiments have sought to examine the relationship between social identity salience and creative behavior. For example, one experiment published in the Journal of Experimental Social Psychology in 2007, asked student participants to create a poster either about "reasons for going to university" or about "fashion at university". It was assumed that in the former case the norm would be to use more words than images and in the latter it would be to use more images than words. Three hours later, participants were asked to create a leaflet to advertise the university either individually or in groups. Here we were interested in whether and how this creative task would be shaped by the group norm. In line with predictions, what we found was that when working in groups (where social identity was salient) participants' creations were in line with the pre-established group norm (to use more images or words), but that when working individually participants were more likely to depart from the norm.

The findings of this and other similar studies support the claim that the nature of people's creative activity depends both on the content of group norms and the degree to which those norms are self-defining. Importantly, this analysis also helps to explain why creativity can involve both divergent thinking ("thinking outside the box") and convergent thinking ("honing in" on a problem) and why it is that one or other of these orientations will tend to predominate for a particular creator in a particular creative context.

Yet while social identification stimulates conformity to norms, it is a mistake to assume that this will lead only to acts of slavish reproduction. For the norms that group members conform to define only one dimension of their creativity. Cubist painters, for 
instance, may adhere to one way of expressing themselves through the use of abstract geometrical figures. However, their creations are likely to diverge on a range of dimensions that are not central to the prevalent norm - for example, in the use of colours, themes, techniques, and so on.

Conformity to norms can also present us with an apparent paradox. For in cases where "being different" is normative, the more group members conform to the group norm the more deviant they will be. In this way, individuals' engagement with, and support for, prevailing forms of group innovation can be seen to depend upon their identification with the group in question and its goals. This point is supported by experiments conducted by Dominic Packer at Lehigh University and Christopher Miners from Queen University in Canada that were published in the Journal of Experimental Social Psychology in 2012 . In these, participants had to act creatively by writing the introduction for a group meeting in which they were going to discuss alcohol use with fellow students. The researchers found that when people acted in terms of personal identity they tended to act creatively in ways that involved disengagement from group norm, but that when they acted in terms of social identity they were more likely to act creatively in ways that involved engaging more intensely with group and its norms.

A similar point emerges of our experiments which tested the hypothesis that that people would be more likely to remain committed to a creative project that was running into trouble if they defined themselves in terms of a shared social identity (as "us" and "we") rather than as individuals ("I" and "me"). The studies were published in the Journal of Organizational Behavior in 2006 and centred on plans to build a municipal childcare centre that, as it progressed over three phases, ran into mounting difficulties (the sandpit was found 
to have traces of toxic elements, the budget was over-running, planning approval was being held up). Participants were randomly assigned to different conditions in which their identity was manipulated either by asking them to focus on what made them similar to other group members or what made them different. In line with predictions, those whose shared social identity had been made salient maintained positive attitudes to the project and gave it increasing support. On the other hand, those whose personal identity had been made salient became increasingly less supportive. In short, shared social identity led people to stick to the group's creative guns. Without it, they cut and run.

At the same time, though, it is apparent that the collective aspects of group creativity is easily overlooked for the very reason that these involve convergent thinking and conformity. Indeed, this becomes clearer once one recognizes that the experimental paradigm that we were using in the above studies had originally been developed to investigate groupthink - a phenomenon which, after the classic work of Irving Janis at Yale University in the 1970s, is generally considered to be the very antithesis of creativity. Nevertheless, we would suggest that although they are routinely denigrated, processes of solidarity and conformity are essential for creative movements to progress because they provide the basis for individuals to cohere around, and extend, a shared enterprise. Indeed, if individuals always ran for cover at the first sign of trouble (as they are prone to do in the absence of shared social identity), revolutionary projects in science, industry, business, and politics would never get off the ground.

\section{Being seen to be creative}


A social identity approach to creativity suggests that group memberships not only determine the creative acts that we perform but also the evaluation of those performed by others. One obvious implication of this claim is that any given product is more likely to be perceived as creative and to be regarded favorably when its creator is considered a member of a psychological ingroup. In other words, in order to dispel the uncertainty that creative products introduce by disrupting the status quo, a creator needs to be seen as 'one of us' who is 'doing it for us'. Indeed, this analysis fits more generally with the social identity approach to leadership that we have discussed extensively elsewhere [see "The New Psychology of Leadership”, SCIENTIFIC AMERICAN Mind, August 2007].

This phenomenon is apparent in a range of settings. For example, in organizational domains 'insiders' are often found to be antagonistic towards outsiders' contributions leading to what management theorists refer to as Not Invented Here (NIH) syndrome. Likewise, in artistic domains, people are typically found to display ethnocentric bias when judging others' creativity. That is, they consider 'our' creators and creations to be superior to 'theirs', and also regard creations (and dimensions of creativity) that valorize 'us' to be superior to those that valorize 'them'.

A topical example of this process is provided by an archival (and as yet unpublished) study conducted in 2013 by Niklas Steffens and colleagues at the University of Queensland. This showed that while the Oscars and BAFTAs are both meant to judge the objective quality of films, since 1968 US actors and actresses have received $80 \%$ of the Oscars for best actor/actress but less than half of the BAFTAs. At the same time British actors and actresses have received nearly half of the corresponding BAFTAs but only just over $10 \%$ of the Oscars. 
This is a phenomenon that we examined more closely in experimental studies that we published in 2008 in the journal Social Influence. These tested the idea that perceptions of creativity are contingent upon judges sharing group membership with creators. For example, in one experiment British participants evaluated suggestions about the future format of a TV show that were said to have been generated in either an ingroup or an outgroup forum (a British or a Dutch website). In another, British students evaluated art work supposedly painted by either an ingroup (British college students) or an outgroup (Dutch college students). Despite the fact that they were always evaluating identical creations (paintings, ideas, adverts), in all these studies participants perceived products that they thought had been generated by the ingroup to be significantly more creative than those that were thought to have been produced by an outgroup.

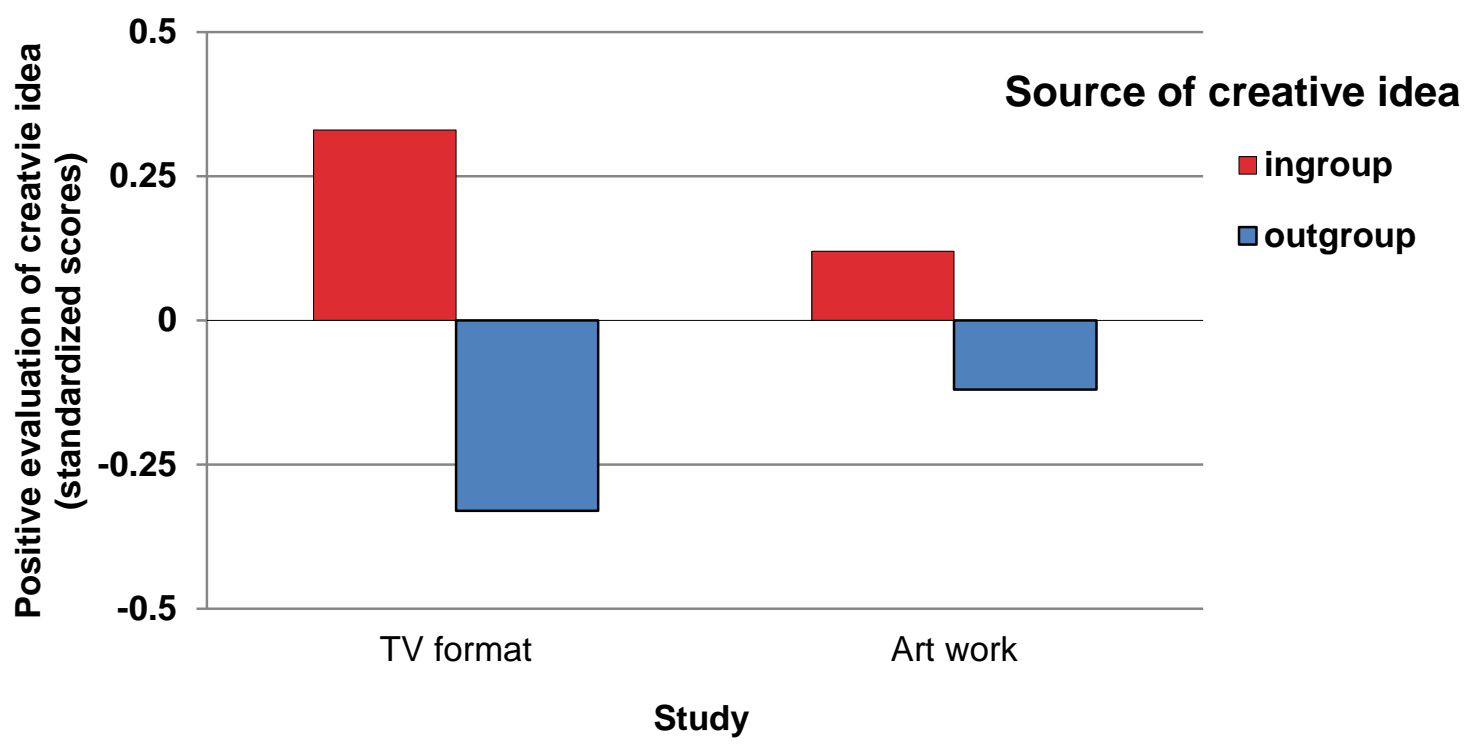

More general evidence of bias in the appreciation of creativity also emerges from cross-cultural work by Susannah Paletz and Kaiping Peng at the University of California 
Berkeley. Research that they published in the Journal of Cross-Cultural Psychology in 2008 the shows that what people actually mean by creativity — and hence how they measure and reward it — varies as a function of their cultural identity. This bias also helps to explain the paradox identified in a 2012 Psychological Science paper by Jennifer Mueller and her colleagues whereby people typical express a considerable amount of support for the general idea of creativity, but nevertheless object to the specific forms of creativity that they encounter in practice.

But in case you thought such patterns were peculiar only to non-scientific domains, a 2006 paper published in Political Psychology by Thomas Morton and colleagues at the University of Exeter suggests that this is far from the case. Their research showed that male scientists viewed theories that explained why men were superior to women to be better and more creative than those that explained why women were superior to men; whereas this pattern was reversed for female scientists. Interestingly too, both these groups believed that the creative research that supported their own identity-based preferences was deserving of more research funding.

\section{Conclusion}

The above analysis suggests that rather than involving entirely different principles, there is a close relationship between the two key components of the creative process: on one hand, acts of creativity (individual behavior that is celebrated for its originality) and, on the other, the appreciation of creativity (social judgments of original ideas and products). More specifically, we argue that processes of self and identity connect these two components, since, as members of groups, our own acts of creativity and our evaluations of the creative 
acts of others both reflect a desire to live out and extend the group values that we share and to challenge and kick against the group values that we don't.

To be creative — and to be celebrated rather than vilified — one thus needs to know what one is departing from and one needs (at some point) an audience that shares an appreciation of one's creativity with members who are willing to embrace the new ways of seeing and behaving that are made possible by one's novel creation. Thus while Picasso was famously scornful of acolytes ("Disciples be damned. It's only the masters that matter, those who create"), without them, it is unlikely that his work would have had anything like the impact it has. To get some sense of this, reflect on the young Steve Jobs wandering around California trying to tout the idea of a home computer to a legion of sceptics who think the home is no place for such a contraption.

As well as new products, it is therefore the creation of new (or transformed) communities that lies at the heart of successful creativity. These provide the basis for appreciation of the creator and they also provide the means to drive forward the change that creativity envisions and that makes it an essential engine of culture. Lacking such community, Van Gogh could find no-one apart from his brother Theo to buy his garish paintings, and the computational models of Yoshisuki Ueda, one of the founders of chaos theory, could be barred from publication by his $\mathrm{PhD}$ supervisor for being too "avant-garde". However, once communities had formed that appreciated this work, the world was never quite the same again.

It is right then, that we study and celebrate the creative genius of individuals. But a full and proper psychology of creativity also requires that we not neglect the groups out of which creators are formed, the groups whose boundaries they seek to extend, and the groups 
through which they have their impact. "I did it my way" may be the appealing anthem of great creators but, as with Sinatra, their success generally also requires promoters, producers, and an approving public.

\section{(The Authors)}

S. ALEXANDER HASLAM is professor of psychology and Australian Laureate Fellow at the University of Queensland in Australia and serves on the board of advisers for Scientific American Mind.

INMA ADARVES-YORNO is a senior lecturer in leadership studies at the University of Exeter in England,

TOM POSTMES is professor of social psychology at the University of Groningen in The Netherlands

\section{(Further reading)}

- Adarves-Yorno, I., Postmes, T., \& Haslam, S. A. (2007). Creative innovation or crazy irrelevance? The contribution of group norms and social identity to creative behavior. Journal of Experimental Social Psychology, 43, 410-416.

- Haslam, S. A., Adarves-Yorno, I., Postmes, T., \& Jans, L. (2013). The collective origins of valued originality: A social identity approach to creativity. Personality and Social Psychology Review, 17, 384 401.

- John-Steiner, V. (2000). Creative collaboration. Oxford: Oxford University Press.

- Mueller, J. S., Melwani, S., \& Goncalo, J. A. (2012). The bias against creativity: Why people desire but reject creative ideas. Psychological Science, 23, 13-17.

$\checkmark$ Packer, D. J., \& Miners, C. T. H. (2012). At the first sign of trouble or through thick and thin? When nonconformity is and is not disengagement from a group. Journal of Experimental Social Psychology, 48, 316-322. 
Suggestions for boxes:

Creativity has a fundamental function for humans as a species, but it also centres on a conundrum. On the one hand, for us to function within a given culture, we have to conform. But, for culture to be possible, we also have to be innovative and creative. Moreover, we also have to tolerate, adapt to, and embrace, the creativity of others. This conundrum can be exemplified by reflecting on the stone-age frescoes in the Paleolithic caves of Lascaux in south-west France or the anarchic music of the Sex Pistols. What type of social system tolerates and stimulates such exceptional displays of creativity? And what is the underlying psychology of those who produced the frescoes and those who appreciated them? In addressing such questions, the scientific study of creativity speaks not just to an important human propensity, but to the essence of the human condition.
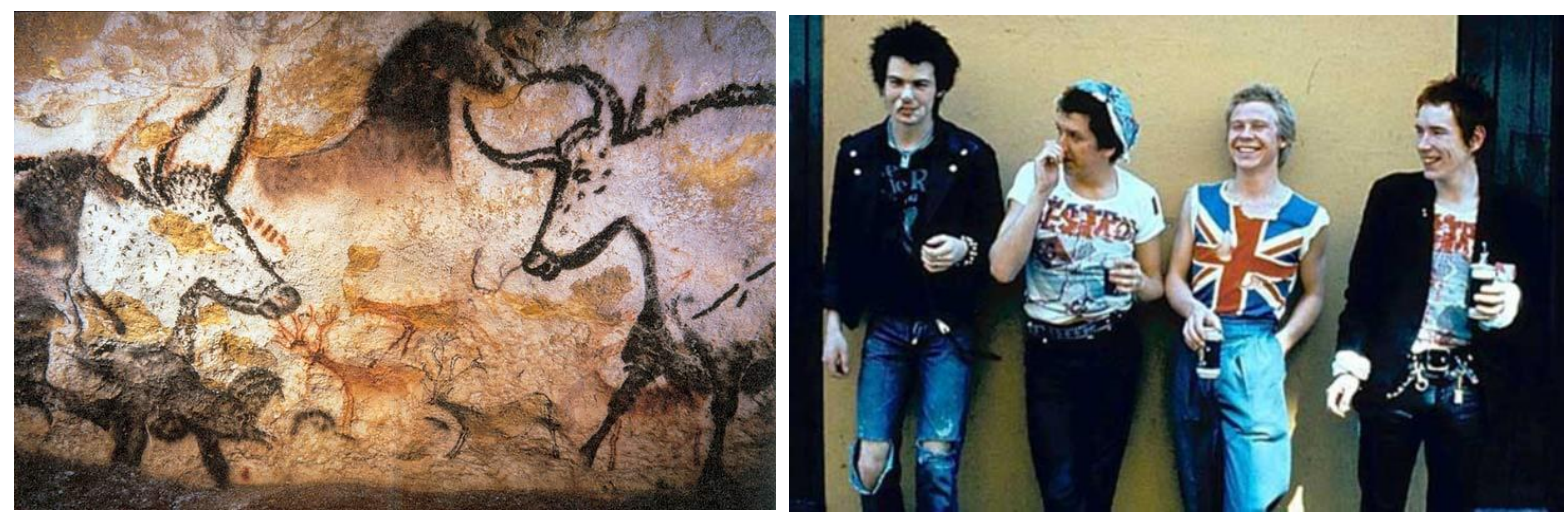

Reference: Richerson, P. J. (2004). Not by genes alone: How culture transformed human evolution. Chicago: University of Chicago Press. 
Groups and creativity 15 